\title{
Chronic Vascular Pulmonary Dysplasia Associated with Neonatal Hyperoxia Exposure in the Rat
}

\author{
STANLEY G. SHAFFER, DIANE O’NEILL, SANDRA K. BRADT, AND DONALD W. THIBEAULT \\ The Children's Mercy Hospital, University of Missouri-Kansas City, School of Medicine, \\ Kansas City, Missouri 64108
}

\begin{abstract}
Chronic sequelae of neonatal hyperoxia was studied in male rats exposed to $0.96-1.0 \mathrm{FiO}_{2}$ for the first 8 days of life. At 58 days of age functional and morphologic cardiopulmonary changes were compared with controls. Right ventricular systolic pressure was measured percutaneously under anesthesia and was increased in the $\mathrm{O}_{2}$ group (29.5 $\mathrm{mm} \mathrm{Hg} \pm 3.1$ versus $23.2 \mathrm{~mm} \mathrm{Hg} \pm 3.5, p<0.001)$. Lung and heart weights were similar between groups. Right ventricular weights however were increased in the $\mathrm{O}_{2}$ group $(0.197 \mathrm{~g} \pm 0.023$ versus $0.175 \mathrm{~g} \pm 0.020, p<0.001)$. Air pressure-volume curves were similar but in the $\mathrm{O}_{2}$ rats saline deflation curves were shifted left and maximal fluid lung volumes were greater $(14.1 \pm 1.2$ versus $12.0 \pm 0.7$ $\mathrm{ml}, p<0.001)$. Pulmonary arteries were perfused at 100 $\mathrm{cm} \mathrm{H}_{2} \mathrm{O}$ with a barium-gel mixture and lungs were fixed at $25 \mathrm{~cm} \mathrm{H}_{2} \mathrm{O}$ with formalin. Microscopic examination of lungs revealed dysplastic changes of alveolar architecture which included irregularly enlarged alveoli and incomplete alveolar septation. Morphometric studies of the lungs showed that the $\mathrm{O}_{2}$ rats had an increased volume proportion of parenchyma $(0.865 \pm 0.020$ versus $0.850 \pm 0.019$, $p<0.05)$, increased mean linear intercept $(72.3 \mu \mathrm{m} \pm 9.5$ versus $53.6 \mu \mathrm{m} \pm 5.0, p<0.001$, decreased number of alveoli per $\mathrm{mm}^{2}(207 \pm 34$ versus $319 \pm 39, p<0.001)$ and fewer small arteries (20-200 $\mu \mathrm{m})$ per $\mathrm{mm}^{2}(8.7 \pm 1.3$ versus $14.9 \pm 2.4, p<0.001)$. The number of small arteries/ 100 alveoli was similar. We conclude that limited and specifically timed neonatal hyperoxia is associated with chronic morphologic and functional cardiopulmonary changes in the adult rat. These changes include a decrease in the number of small pulmonary arteries, elevated right ventricular pressure, and emphysema-like changes in the air spaces. (Pediatr Res 21: 14-20, 1987)
\end{abstract}

\section{Abbreviations}

RA, room air

P-V, pressure-volume

MLV, maximal lung volume

$\mathrm{C}_{30-60}$, static lung compliance

$\mathrm{C}_{30-60 / \mathrm{MLV}}$, specific lung compliance

$R V$, right ventricle

$L V+S$, left ventricle plus septum

LM, mean linear intercept

ISA, internal surface area

$\mathrm{MLV}_{45}, \mathrm{MLV}$ at $45 \mathrm{~cm} \mathrm{H}_{2} \mathrm{O}$ transpulmonary pressure

Received May 27. 1986: accepted August 6, 1986.

Correspondence and reprint address Donald w. Thibeault, M.D., Professor of Pediatrics, Children's Mercy Hospital, 24th and Gillham, Kansas City, MO 64108.
$\mathrm{MLV}_{14}$, maximal saline lung volume at $14 \mathrm{~cm} \mathrm{H} \mathrm{H}_{2} \mathrm{O}$ transpulmonary pressure

Exposure of the lung to increased concentrations of inspired oxygen is associated with multiple toxic effects. These include pulmonary endothelial damage, intraalveolar hemorrhage, development of pulmonary edema, and decreased pulmonary compliance (1-5). The neonate tolerates exposure to hyperoxia with less acute injury than does the adult (6-14). To the neonate, however, hyperoxia presents additional risks by threatening normal growth and development of the lung. In tissue culture, hyperoxia inhibits the growth and extension of pulmonary endothelial tissue (15). In vivo, hyperoxia has been associated with decreased DNA synthesis, decreased lung growth, delayed maturation of alveolar structures, and dysplastic pulmonary vascular development $(12,13,16-20)$.

The dose and timing dependent relationships of oxygen-induced pulmonary injury are not entirely clear. Long-term sequelae of neonatal hyperoxia exposure have only recently been investigated. Roberts et al. (19) exposed newborn rats to hyperoxia for the first 6 days of life and studied pulmonary changes during the following $2 \mathrm{wk}$. Abnormalities in lung growth and morphology were initially apparent but became attenuated during the observed recovery period. By 2 wk of recovery the lungs were similar to controls in most respects. However, Wilson et al. (20) investigated the long-term sequelae of prolonged hyperoxia exposure in the young rat.

Oxygen exposure was begun at 10 days of age and continued for 2-8 wk. Neonatal hyperoxia exposure for as brief a period as 2 wk was found to be associated with impaired alveolar growth and vascular abnormalities in the adult. These investigations suggest therefore that pulmonary growth abnormalities may accompany either acute or prolonged hyperoxia exposure. The results of these studies differ, however, regarding potential for recovery and long-term implications of these pulmonary changes.

The risk of permanent lung damage due to hyperoxia exposure may be related to the timing as well as the duration and concentration of exposure. Burri (21) has reviewed postnatal lung growth in rats and observed a period of tissue proliferation which occurs between 4 and 13 days of postnatal life. It is during this period that alveolar number, surface area, and capillary volume increase through a process of secondary alveolar septal formation. Hyperoxia during this phase of development of the lung may inhibit alveolar septation and thereby cause permanent alterations in morphology and function.

The purpose of this study is to expose neonatal rats to hyperoxia during the first 8 days of life which is similar to the design of Roberts et al. (19) followed by a 52-day recovery period similar 
to the design of Wilson et al. (20). The chronic effects of this specifically timed and limited neonatal hyperoxia exposure will be assessed both by morphometric and functional cardiopulmonary studies.

\section{MATERIALS AND METHODS}

Oxygen exposure. One hundred eight Sprague Dawley newborn rats, $2-18 \mathrm{~h}$ of age with their dams, were divided into two groups and received hyperoxia $\left(0.96-1.0 \mathrm{FiO}_{2}\right)$ or room air for 8 full days. The animals were housed in regular rat cages which were placed into two $12 \mathrm{ft}^{3}$ lucite chambers. Each chamber received either humidified $\mathrm{O}_{2}$ or RA at 10 liter flow per min. Oxygen concentration was measured continually with an oxygen analyzer (Ventronics, Temecula, $\mathrm{CA}$ ). The $\mathrm{CO}_{2}$ concentration was measured intermittently and did not exceed $0.2 \%$. Dams were given rat food and water ad libitum and were rotated at 24$\mathrm{h}$ intervals between $\mathrm{O}_{2}$ and RA groups. At the completion of 8 full days, the $\mathrm{O}_{2}$ group was abruptly returned to room air. The animals were weighed daily for the first 10 days of life, every 2 nd day through 11-22 days, and weekly until 60 days of age. Rats were weaned at 22 days of age and were fed rat food until sacrificed at 60 days of age.

In vivo physiologic measurements. At 16 and $90 \mathrm{~h}$ following abrupt termination of hyperoxia, arterial oxygen saturations were measured in $\mathrm{O}_{2}$ and $\mathrm{RA}$ groups of rats while they breathed RA. Oxygen saturations were measured over the right carotid artery using a pulse oximeter (Nellcor Inc., Hayward, CA).

At 58 days of age the rats were lightly anesthetized with Halothane and right ventricular systolic and diastolic pressures were measured. A 1-inch 23-gauge needle was inserted percutaneously at the left ziphoid sternal notch and directed transdiaphragmatically into the right heart. A pressure transducer (Millar Instruments, Inc., Houston, TX; model PR249) was placed in the needle hub prior to the puncture. The system was calibrated with a water manometer and zeroed at the level of the right atrium. The pressure wave form was recorded on an Electronics for Medicine 6-channel recorder. Right ventricular pressures were calculated from the mean of 10 consecutive pressure curves.

In $19 \mathrm{O}_{2}$ rats and $17 \mathrm{RA}$ rats, right ventricular pressures were repeated twice over a 48 -h period. The first measurement was obtained while rats breathed RA mixed with halothane. The second measurement was obtained while rats breathed $85 \% \mathrm{O}_{2}$ mixed with halothane. The purpose of this was to determine if right ventricular systolic pressure, and therefore the peak pulmonary artery pressure in the $\mathrm{O}_{2}$ rats, was labile and could be decreased by elevating the inspired $\mathrm{O}_{2}$ concentration.

Preparation of heart and lungs. At 60 days of age, $\mathrm{O}_{2}$ and RA groups of rats were separated at random into three groups. All animals were anesthetized with $50 \mathrm{mg} / \mathrm{kg}$ of sodium pentobarbital injected intraperitoneally.

Rats from the first group were used to obtain lung weights, protein, and DNA content. Animals were sacrificed by exsanguination from the abdominal aorta. Lungs were excised and wet weights recorded. The right lung was frozen for later analysis of DNA and protein content (22-23). The left lung was used for dry weight measurement.

Lungs from the second group were used to obtain P-V curves. The trachea of each rat was cannulated and the animal was denitrogenated by breathing $100 \%$ oxygen for $10 \mathrm{~min}$. Lungs were then collapsed by occluding the tracheal cannula. Immediately following cessation of respirations the animals were exsanguinated. The collapsed lungs and heart were excised en bloc and a P-V curve was obtained with either air or saline.

Air curves were performed by inflating the collapsed lung during a 30-min period to a maximum pressure of $45 \mathrm{~cm} \mathrm{H}_{2} \mathrm{O}$. Volume was read directly from a calibrated syringe and the pressure was measured with a water manometer. Deflation was accomplished over $15 \mathrm{~min}$, with volumes recorded at $5 \mathrm{~cm} \mathrm{H}_{2} \mathrm{O}$ pressure decrements to a pressure of $5 \mathrm{~cm} \mathrm{H}_{2} \mathrm{O}$; thereafter volumes were recorded at $1 \mathrm{~cm} \mathrm{H}_{2} \mathrm{O}$ decrements. During deflation, readings were taken only if the pressure remained constant for $1 \mathrm{~min}$. Saline pressure curves were obtained using the method of Mead et al. (24). A maximum pressure of $14 \mathrm{~cm} \mathrm{H}_{2} \mathrm{O}$ was used.

P-V curves were constructed by plotting transpulmonary pressure versus volume. Volume was also expressed as a percentage of MLV and as the volume per $g$ of dry lung weight. $\mathrm{C}_{30-60}$ was measured as the slope of the straight part of the V-P deflation curve between 30 and $60 \%$ of MLV. $\mathrm{C}_{30-60} / \mathrm{MLV}$ was calculated by dividing the static compliance by the MLV.

The third group of animals was used for morphometric analysis. Each animal was killed by exsanguination. The thorax was widely split and the trachea was cannulated just above the carina. The pulmonary artery was cannulated via the right ventricle with a 13-gauge blunt needle and tied into place. The pulmonary artery was injected at $100 \mathrm{~cm} \mathrm{H}_{2} \mathrm{O}$ pressure for 4 min with a radioopaque barium gelatin mixture heated to $60^{\circ} \mathrm{C}(25)$. The heart was excised and the right ventricle was packed with cotton and the entire heart was fixed in $10 \%$ buffered formalin. The $R V$ was dissected from the $L V+S$ and each was weighed separately and expressed as the ratio $\mathrm{RV} / \mathrm{LV}+\mathrm{S}(26)$. The lungs were inflated at $25 \mathrm{~cm} \mathrm{H}_{2} \mathrm{O}$ with $10 \%$ buffered formalin and perfused at this pressure for $72 \mathrm{~h}$.

After fixation, lung volume was determined by fluid displacement (27). A calibrated marker was placed on the lung at the level of the pulmonry artery and radiographs were obtained. Pulmonary arteriograms were assessed using a dissecting microscope to measure the left pulmonary artery diameter 5 and 25 $\mathrm{mm}$ distal to the main pulmonary artery.

Transverse sections of the superior, middle, and inferior portions of the left lung were processed and embedded in paraffin. The entire transverse sections were cut $5-\mu$ thick and were stained with hematoxylin and eosin or Miller Van Gieson stain.

Volume proportions of the lung nonparenchymal and parenchymal structures were assessed using the point counting system (28). Point counting of nonparenchyma was carried out under low magnification $(\times 35)$. The entire area of each section of the left lung was examined and the number of hits on pleura, septa, peribronchial and perivascular tissue, terminal bronchi, and larger bronchi and vessels $(>200 \mu \mathrm{m})$ were recorded. Using a higher magnification $(\times 100)$ and covering 20 or more consecutive fields and at least 500 points, the number of parenchymal hits on alveolar air spaces, alveolar ducts, respiratory bronchioles, septal tissue, and vessels $\leq 200 \mu \mathrm{m}$ were counted.

Lm was measured using crossed hair lines of known length. Using $\times 100$ magnification, 20 consecutive fields were counted for each lung (28). The ISA of the lungs was calculated using the mean linear intercept method from the equation: (28)

$$
\mathrm{ISA}=\frac{4 \lambda \mathrm{V}}{\mathrm{Lm}}
$$

where $\mathrm{V}$ is the volume of the lung and $\lambda$ equals the fraction of lung containing parenchyma.

Vessel and alveolar counts were obtained by counting the number of small arteries (25-200 $\mu \mathrm{m}$ external diameter) and alveoli included on a $0.36 \mathrm{~mm}^{2}$ grid consisting of 36 squares. A minimum of 20 consecutive fields were counted on each of the three lung sections. At least 1500 alveoli were also counted. From these data the number of alveoli $/ \mathrm{mm}^{2}$, small arteries $/ \mathrm{mm}^{2}$, and number of arteries per 100 alveoli were calculated.

Arterial wall medial thickness and extent of muscularization were categorized by vessel external diameters $(25-50,51-100$, $101-200,201-300,301-400,401-500,501-1000$, or $>1000$ $\mu \mathrm{m})$. External diameter was defined as the distance between the outer edges of the external elastic lamina. Medial thickness was defined as the distance along the diameter from the luminal 
surface of the internal elastic lamina to the outer edge of the external lamina. The percent medial wall thickness was calculated by $(25)$ :

\section{$2 \times$ medial thickness $\times 100$ external diameter}

Muscle tissue was also identified as either circular or oblique (29). Muscle tissue was assessed in 30 consecutive vessels of external diameter 25-50 and 51-100 $\mu \mathrm{m}$; and in all arterial vessels 101 to $1000 \mu \mathrm{m}$ in the three sections from the left lung.

Morphologic data were not corrected for tissue shrinkage due to fixation or processing. The results of each analysis were assessed statistically by unpaired Student's $t$ test. Results are expressed as mean values $\pm 1 \mathrm{SD}$.

\section{RESULTS}

Growth. All surviving animals appeared healthy at the end of 8 days of hyperoxia and at 60 days of age. However, there was a $3.0 \%$ mortality rate in the oxygen group which occurred during the hyperoxia. There were no significant body weight differences between RA and $\mathrm{O}_{2}$ groups at any age.

In vivo physiologic measurements. Percent oxygen saturation measured in $\mathrm{O}_{2}$ rats $16 \mathrm{~h}$ after abrupt withdrawal from hyperoxia was significantly decreased compared to RA controls $(90 \% \pm 3$ versus $97 \% \pm 2, p<0.001$ ). At 90 h of age, however, there was no longer a difference, with oxygen saturation being $96 \% \pm 3$ in the $\mathrm{O}_{2}$ group.

At 58 days of age, systolic right ventricular pressures measured while breathing RA were significantly elevated in the oxygen group (29.5 mm Hg \pm 3.1 ) compared to RA controls $(23.2 \mathrm{~mm}$ $\mathrm{Hg} \pm 3.5, p<0.001)$. Right ventricular pressures in either group were not significantly different when the inspired oxygen concentration was increased to 0.85 (Fig. 1).

Biochemical analysis. There was a small but significant decrease in the total lung DNA in the $\mathrm{O}_{2}$ group $(4.5 \mathrm{mg} \pm 0.3$ versus $4.9 \mathrm{mg} \pm 0.5, p<0.05)$ as was the ratio of DNA to dry lung weight $(28.2 \pm 2.7$ versus $32.5 \pm 3.6, p<0.001)$. A small elevation was observed both in the total lung protein in the $\mathrm{O}_{2}$ group $(118.5 \mathrm{mg} \pm 6.5$ versus $113.5 \mathrm{mg} \pm 6.8, p<0.05)$ as was the protein to DNA ratio $(16.8 \pm 1.2$ versus $14.8 \pm 2.1, p<$ 0.005 ) (Table 1).

Cardiac chamber size. Total heart weight and LV $+\mathrm{S}$ weight were similar in the two groups. In the oxygen group, RV weight was significantly greater $(0.197 \mathrm{~g} \pm 0.023$ versus $0.175 \mathrm{~g} \pm 0.020$,

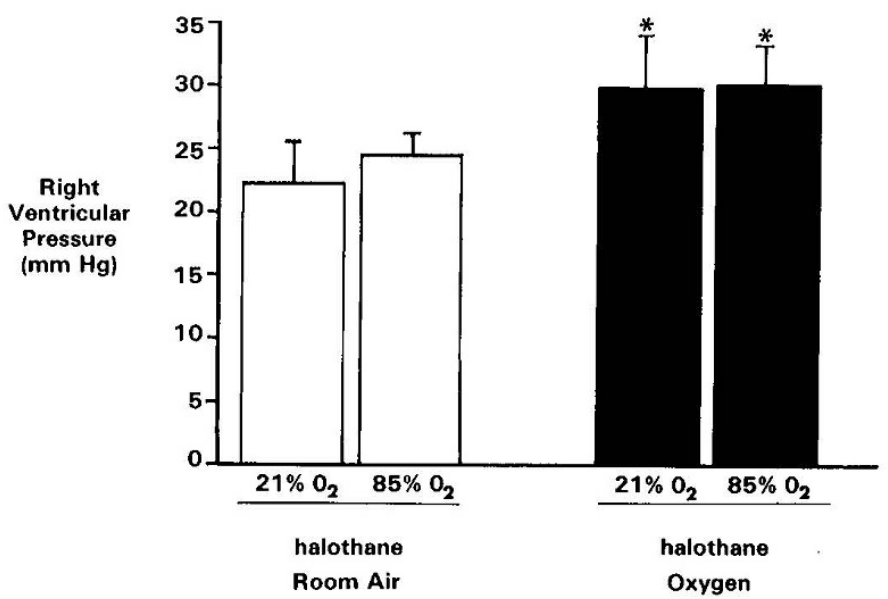

Fig. 1. The chronic effects of neonatal hyperoxia on right ventricular pressure. The hyperoxic animals (dark columns) had a significant increase in pressure compared to RA controls $(p<0.001)$. Ventricular pressure measured while breathing room air or $0.85 \mathrm{O}_{2}$ did not alter the results. $p<0.001)$. The $\mathrm{RV} / \mathrm{LV}+\mathrm{S}$ ratio was also significantly greater among $\mathrm{O}_{2}$ rats $(0.305 \pm 0.034$ versus $0.271 \pm 0.021, p<0.001)$.

Lung volume and P-V curves. $\mathrm{MLV}_{45}$, dry lung weights, dry lung weight per $g$ body weight, and MLV per $g$ body weight were similar. The air P-V curves were similar, whether expressed as pressure versus lung volume, percent MLV or lung volume per g dry lung weight. Similarly, static and specific compliances were not different (Table 2).

However, $\mathrm{MLV}_{14}$ was significantly elevated in the $\mathrm{O}_{2}$ group compared to controls $(14.1 \mathrm{ml} \pm 1.2$ versus $12.0 \mathrm{ml} \pm 0.7 p<$ $0.001)$. MLV per $g$ of dry lung weight and MLV per $g$ of body weight were significantly larger in the oxygen group (Table 2). Lung dry weight and lung dry weight per $g$ of body weight were not different.

The saline P-V curve expressed as pressure versus percent of MLV was significantly shifted to the left at $6 \mathrm{~cm} \mathrm{H}_{2} \mathrm{O}$ transpulmonary pressure (Fig. 2). The P-V curves, when expressed as pressure versus volume per $\mathrm{g}$ dry lung weight or lung volume were also significantly different (Fig. 3). That is, at any given transpulmonary pressure there was significantly more fluid in the lung. Both the static and the specific compliances were also significantly elevated in the oxygen group (Table 2 ).

Morphometric studies. The alveolar architecture was disrupted in $\mathrm{O}_{2}$ rats illustrated by the emphysema-like appearance of the lung. Alveolar septa appear foreshortened and alveoli are enlarged and irregular (Fig. 4). In the oxygen group alveoli were larger in size (mean linear intercept $72.3 \mu \mathrm{m} \pm 9.5$ versus 53.6 $\mu \mathrm{m} \pm 5.0, p<0.001)$ and the number of alveoli $/ \mathrm{mm}^{2}$ was

Table 1. Body and lung wt and biochemical measurements in $15 R A$ and 16 hyperoxic-treated rats

\begin{tabular}{lccc}
\hline \multicolumn{1}{c}{ Parameter } & $\mathrm{RA}$ & $\mathrm{O}_{2}$ & $p$ \\
\hline Body wt (g) & $276 \pm 11$ & $274 \pm 10$ & $\mathrm{NS}$ \\
Lung wet wt (g) & $1.184 \pm 0.067$ & $1.125 \pm 0.123$ & $\mathrm{NS}$ \\
Lung dry wt (g) & $0.239 \pm 0.019$ & $0.253 \pm 0.024$ & $\mathrm{NS}$ \\
$\begin{array}{c}\text { Total lung DNA } \\
\text { (mg) }\end{array}$ & $4.9 \pm 0.5$ & $4.5 \pm 0.3$ & $<0.05$ \\
$\begin{array}{c}\text { Lung DNA/lung } \\
\quad \text { dry wt (mg/g) }\end{array}$ & $32.5 \pm 3.6$ & $28.2 \pm 2.7$ & $<0.001$ \\
$\begin{array}{c}\text { Total lung protein } \\
\quad(\mathrm{mg})\end{array}$ & $113.5 \pm 6.8$ & $118.5 \pm 6.5$ & $<0.05$ \\
$\begin{array}{l}\text { Protein/DNA } \\
\text { rote }\end{array}$ & $14.8 \pm 2.1$ & $16.8 \pm 1.2$ & $<0.005$ \\
\hline
\end{tabular}

Table 2. P-V measurements and compliances in $R A$ and hyperoxic-treated rats

\begin{tabular}{|c|c|c|c|}
\hline & $\begin{array}{c}\mathrm{RA} \\
(n=14)\end{array}$ & $\begin{array}{l}\text { Hyperoxic } \\
(n=12)\end{array}$ & $p$ \\
\hline \multicolumn{4}{|l|}{ Air P-V data } \\
\hline Max lung vol (ml) & $14.2 \pm 1.3$ & $13.9 \pm 1.1$ & NS \\
\hline $\begin{array}{l}\text { Lung dry wt/body } \\
\text { wt }\end{array}$ & $0.088 \pm 0.007$ & $0.089 \pm 0.006$ & NS \\
\hline $\begin{array}{l}\text { Max lung vol/body } \\
\text { wt (ml/g) }\end{array}$ & $0.051 \pm 0.005$ & $0.050 \pm 0.004$ & NS \\
\hline $\begin{array}{l}\text { Max lung vol/dry } \\
\text { lung wt }(\mathrm{ml} / \mathrm{g})\end{array}$ & $58.8 \pm 5.9$ & $56.4 \pm 4.2$ & NS \\
\hline $\mathrm{C}_{30-60} \mathrm{ml} / \mathrm{cm} \mathrm{H} \mathrm{H}_{2} \mathrm{O}$ & $1.372 \pm 0.205$ & $1.376 \pm 0.150$ & NS \\
\hline $\mathrm{C}_{30-60} / \mathrm{MLV}$ & $0.097 \pm 0.01$ & $0.098 \pm 0.007$ & NS \\
\hline Saline P-V data & $(n=9)$ & $(n=12)$ & \\
\hline Max lung vol (ml) & $12.0 \pm 0.7$ & $14.1 \pm 1.2$ & $<0.001$ \\
\hline $\begin{array}{l}\text { Lung dry wt/body } \\
\text { wt }\end{array}$ & $0.088 \pm 0.003$ & $0.088 \pm 0.005$ & NS \\
\hline $\begin{array}{l}\text { Max lung vol/body } \\
\text { wt (ml/g) }\end{array}$ & $0.042 \pm 0.003$ & $0.048 \pm 0.003$ & $<0.001$ \\
\hline $\begin{array}{l}\text { Max lung vol/dry } \\
\text { lung wt }(\mathrm{ml} / \mathrm{g})\end{array}$ & $48.3 \pm 3.7$ & $55.0 \pm 5.1$ & $<0.002$ \\
\hline $\mathrm{C}_{30-60} \mathrm{ml} / \mathrm{cm} \mathrm{H} \mathrm{H}_{2} \mathrm{O}$ & $1.374 \pm 0.214$ & $1.869 \pm 0.328$ & $<0.002$ \\
\hline $\mathrm{C}_{30-60} / \mathrm{MLV}$ & $0.111 \pm 0.011$ & $0.132 \pm 0.013$ & $<0.002$ \\
\hline
\end{tabular}




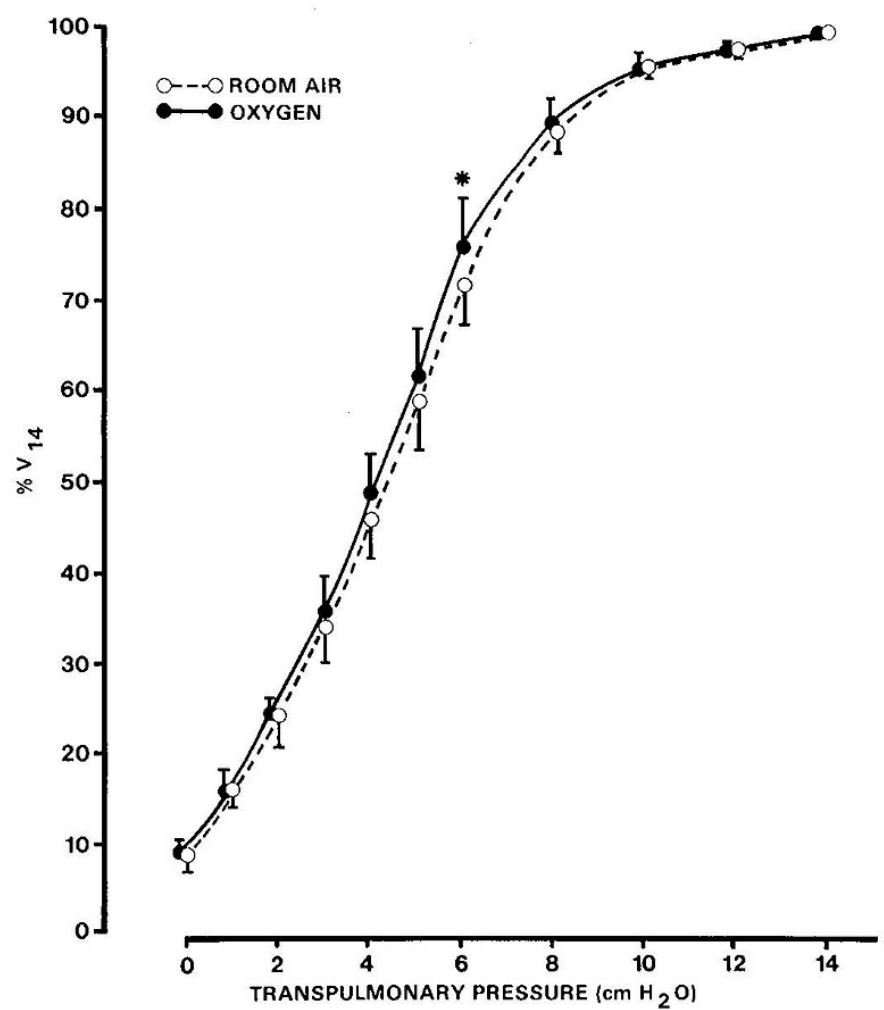

Fig. 2. Static deflation saline-filled P-V curve in room air and oxygen groups. Volume (mean $\pm \mathrm{SD}$ ) is expressed as percent of volume at 14 $\mathrm{cm} \mathrm{H}_{2} \mathrm{O}\left(\mathrm{V}_{14}\right)$. The oxygen group has significantly more volume at $6 \mathrm{~cm}$ $\mathrm{H}_{2} \mathrm{O}$ transpulmonary pressure $(p<0.05)$.

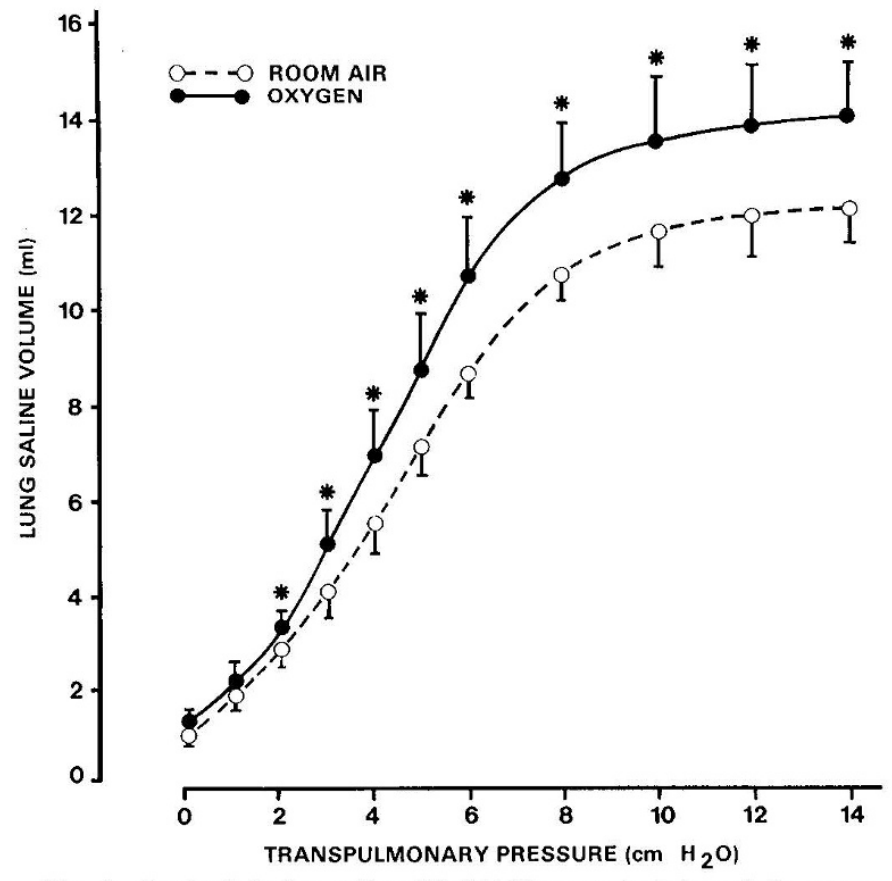

Fig. 3. Static deflation saline-filled $\mathrm{P}-\mathrm{V}$ curve in $\mathrm{RA}$ and $\mathrm{O}_{2}$ group. The actual liquid lung volume $(\mathrm{ml})$ is plotted against the transpulmonary pressure. The asterisks indicate a significant increase of lung volume (mean $\pm \mathrm{SD})$ in the oxygen group $(p<0.005)$.

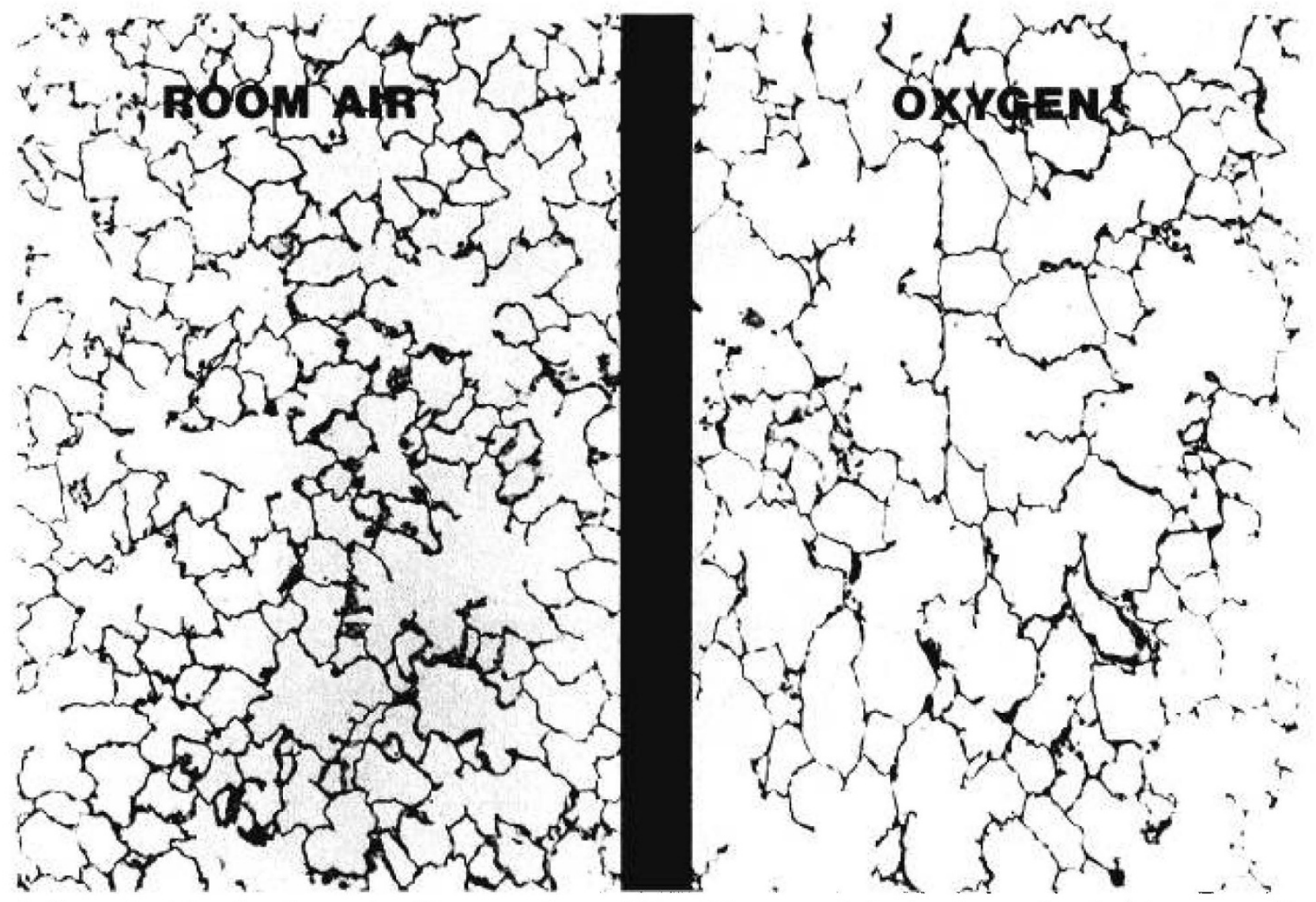

Fig. 4. Contrasting light microphotographs of lung parenchyma of RA and $\mathrm{O}_{2}$ groups. Both microphotographs taken at same magnification, $\times 160$. Note the large alveoli in the $\mathrm{O}_{2}$ group. 
significantly decreased $(207 \pm 34$ versus $319 \pm 39, p<0.001)$. There was a small but significant increase in the volume proportion of parenchyma in the $\mathrm{O}_{2}$ group $(0.865 \pm 0.020$ versus 0.850 $\pm 0.019, p<0.05$ ) (Table 3).

Parenchymal air space (sum of the space occupied by alveoli, alveolar ducts, and respiratory bronchioles) was also increased in the $\mathrm{O}_{2}$ group $(64.0 \% \pm 5.0$ versus $57.9 \% \pm 3.1, p<0.001)$. The internal surface area of the lungs was significantly decreased in the $\mathrm{O}_{2}$ group $\left(6250 \mathrm{~cm}^{2} \pm 720\right.$ versus $8039 \mathrm{~cm}^{2} \pm 1225, p<$ $0.001)$.

From arteriogram measurements, the external diameter of the left pulmonary artery 5 and $25 \mathrm{~mm}$ distal to the main pulmonary artery was significantly smaller in the oxygen group $(1.1 \mathrm{~mm} \pm$ 0.2 versus $1.4 \mathrm{~mm} \pm 0.2, p<0.001$; and $0.3 \mathrm{~mm} \pm 0.1$ versus $0.5 \mathrm{~mm} \pm 0.1, p<0.001)$.

The number of small arteries (25-200 $\mu \mathrm{m}$ external diameter) per $\mathrm{mm}^{2}$ was significantly decreased in the $\mathrm{O}_{2}$ group compared to controls $(8.7 \pm 1.3$ versus $14.4 \pm 2.4, p<0.001)$. However, the number of small arteries per 100 alveoli as well as the number of alveoli per arteries were not different (Table 3).

When vessels containing only circular muscle were assessed, there was an increase in the percent medial wall thickness of arteries of all sizes in the hyperoxic animals (Fig. 5). However, the percentage of vessels $101-1000 \mu \mathrm{m}$ containing oblique muscle was decreased in the $\mathrm{O}_{2}$ group. In fact, in arteries of the 401$1000 \mu \mathrm{m}$ size, there was no oblique muscle in the $\mathrm{O}_{2}$ group, whereas in the RA group $91 \%$ of these arteries contained oblique muscle.

In $\mathrm{O}_{2}$ rats there was distal extension of medial muscle as evidenced by a significant increase in the percentage of small vessels (25-100 $\mu \mathrm{m}$ external diameter) containing circular muscle (Fig. 6).

\section{DISCUSSION}

The present investigation demonstrates that hyperoxia exposure limited to the neonatal period is associated with cardiovas-

Table 3. Lung morphometrics in RA and hyperoxic-treated rats

\begin{tabular}{|c|c|c|c|c|c|}
\hline & RA & $(n)$ & $\mathrm{O}_{2}$ & $(n)$ & $p$ \\
\hline $\begin{array}{l}\text { Fraction of lung volume nonparen- } \\
\text { chyma* }\end{array}$ & $0.150 \pm 0.003$ & (17) & $0.135 \pm 0.003$ & (13) & $<0.05$ \\
\hline $\begin{array}{l}\text { Fraction of lung volume paren- } \\
\text { chyma }\end{array}$ & $0.850 \pm 0.019$ & & $0.865 \pm 0.020$ & & $<0.05$ \\
\hline Fraction of lung volume airspace $\dagger$ & $0.579 \pm 0.031$ & & $0.640 \pm 0.050$ & & $<0.001$ \\
\hline $\begin{array}{l}\text { Fraction of lung volume alveolar } \\
\text { septa }\end{array}$ & $0.232 \pm 0.024$ & & $0.199 \pm 0.189$ & & $<0.001$ \\
\hline No. of small arteries $/ \mathrm{mm}^{2} \ddagger$ & $14.9 \pm 2.4$ & $(18)$ & $8.7 \pm 1.3$ & $(15)$ & $<0.001$ \\
\hline No. of alveoli $/ \mathrm{mm}^{2}$ & $319 \pm 39$ & & $207 \pm 34$ & & $<0.001$ \\
\hline No. of arteries/100 alveoli & $4.5 \pm 0.7$ & & $4.3 \pm 0.8$ & & NS \\
\hline No. of alveoli/artery & $22.7 \pm 4.0$ & & $24.4 \pm 5.9$ & & NS \\
\hline Diameter of left PA $(\mathrm{mm}) \S$ & & $(11)$ & & $(10)$ & \\
\hline $5 \mathrm{~mm}$ distal to main PA & $1.4 \pm 0.2$ & & $1.1 \pm 0.2$ & & $<0.001$ \\
\hline
\end{tabular}

* Nonparenchyma includes: terminal bronchioles and larger airways, vessels $>200 \mu \mathrm{m}$, and pleura.

$\uparrow$ Parenchymal air space includes: respiratory bronchioles, alveolar ducts, and alveoli.

$\ddagger$ Arteries $\geq 25 \mu \mathrm{m}$ and $\leq 200 \mu \mathrm{m}$.

$\S$ Pulmonary artery.

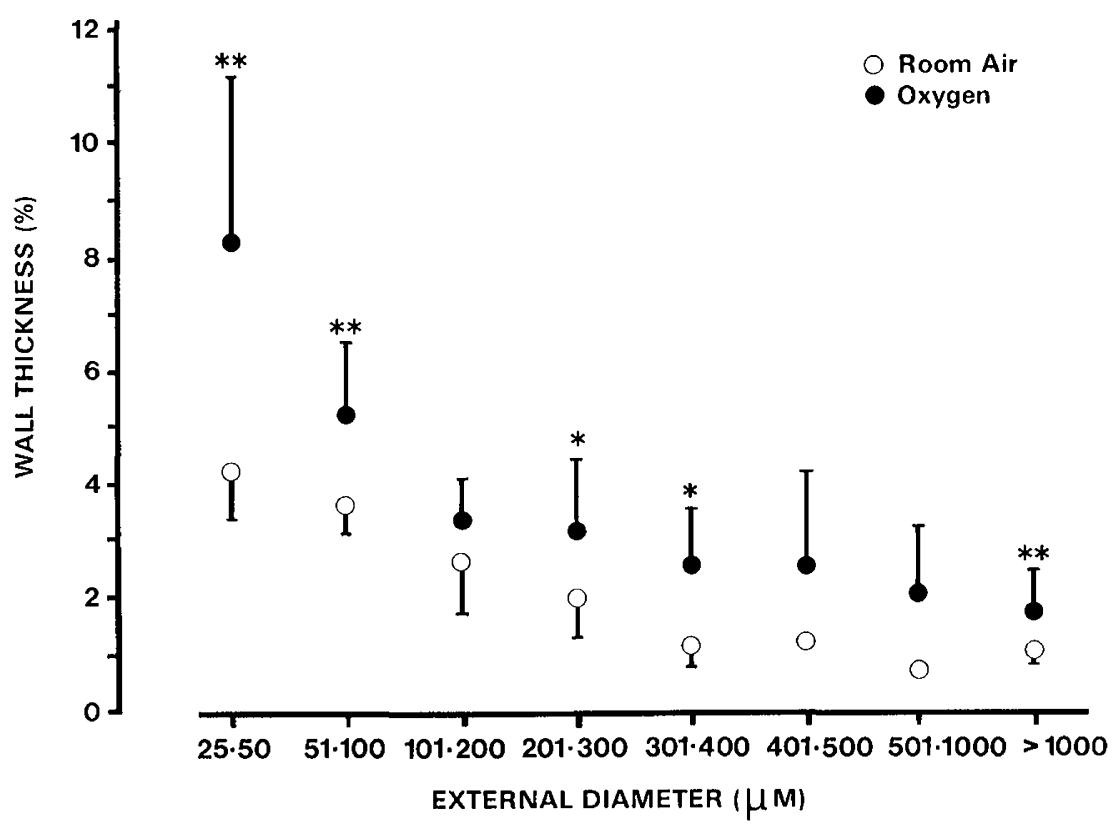

Fig. 5. Percent medial wall thickness (mean $\pm \mathrm{SD}$ ) of vessels containing only circular muscle versus external diameter of vessels $(\mu \mathrm{m})$ in $\mathrm{RA}$ and $\mathrm{O}_{2}$ groups. One and two asterisks indicate $p<0.05$ and $p<0.01$, respectively. There were not enough 401 to $1000 \mu \mathrm{m}$ vessels in RA animals with only circular muscle to derive SDs. 


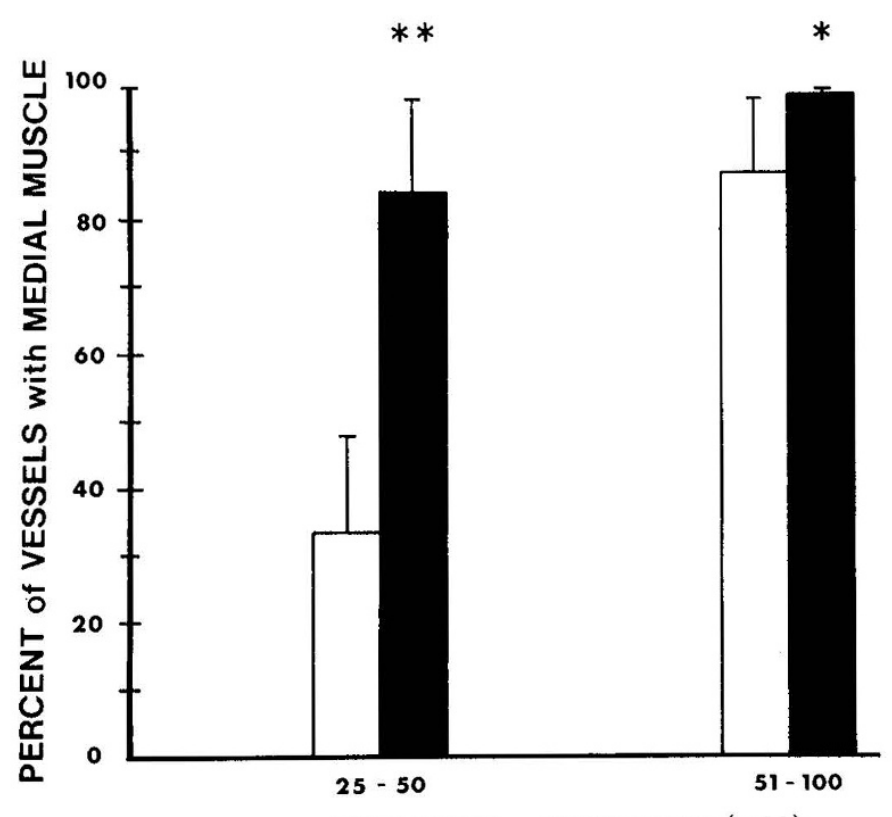

EXTERNAL DIAMETER $(\mu M)$

Fig. 6. Percent of pulmonary arterioles (mean $\pm 1 \mathrm{SD}$ ) 25 to $100 \mu \mathrm{m}$ that have medial muscle. The RA animals are identified by the open columns and the $\mathrm{O}_{2}$ animals by the solid columns. One and two asterisk represent $p<0.03$ and $p<0.0002$, respectively.

cular and pulmonary sequelae in the adult rat. We found adult morphologic changes following 8 days of neonatal hyperoxia exposure similar to those reported to occur after more extended exposure in older rats (20). Furthermore, we have extended the use of the rat model to include study of pulmonary and cardiovascular functional changes which accompany these structural changes.

Exposure of the developing lung to increased oxygen concentration has previously been shown to disrupt lung growth (12, $13,16-18,20)$. Decreased long-term lung growth in the present study was suggested by the small but statistically significant decrease in total lung DNA and the total lung DNA to dry lung weight ratio. However, the small increase in total lung protein and the protein to DNA ratio along with the morphologic changes support an altered lung growth or dysplasia rather than decreased lung growth. Decreased DNA content may occur secondary to malnutrition associated with hyperoxia as well as by a direct oxygen toxic effect $(18,30)$. Malnutrition, however, would be unlikely in the present study since body weights were not different from controls either during oxygen exposure or during recovery. Alteration of lung growth, therefore, occurred in the absence of generalized body growth retardation.

Chronic tissue changes were apparent from saline P.V curves which demonstrated less elastic recoil, increased lung volume, and increased compliance.

Morphologically, hyperoxia-exposed lungs were characterized by dysplastic changes in both alveolar and pulmonry vascular structures. Alveolar size and shape were extremely irregular. Alveolar septa appeared foreshortened or absent resulting in enlarged air spaces. Emphysema-like changes were reflected in lung morphometrics by an increased volume proportion of parenchyma, increased mean linear intercept, decreased alveolar number, and decreased internal lung surface area. Similar lung histology was reported by both Wilson et al. (20) and Bucher and Roberts (18).

Burri (21) has shown that rapid alveolar growth takes place in the normal rat between 4 and 13 days of age. The present investigation suggests that hyperoxia exposure during this period results in acute inhibition of alveolar development, specifically the inhibition of secondary septation. Following hyperoxia ex- posure, sufficient catch-up growth fails to occur and total alveolar number in the mature animal remains reduced. The finding of reduced alveolar number in the adult rat following neonatal hyperoxia exposure is similar to the effects of prolonged hyperoxia exposure in young rats $(20,31)$. Roberts et al. (19) exposed newborn rats to more than 0.95 inspired oxygen concentrations but for only for the first 6 days postnatally (19). In their study morphologic changes were attenuated by 2 wk of recovery. We assume that both timing and duration of neonatal hyperoxia exposure may be critical events determining alveolar number and morphology in the adult.

Pulmonary vascular changes associated with hyperoxia exposure include a decreased diameter of large pulmonary vessels and a striking decrease in the number of small pulmonary arterial vessels. Hyperoxia is known to inhibit vascular endothelial growth in vitro (15). We speculate that exposure to hyperoxia during pulmonary growth impairs branching or extension of pulmonary vessels and decreases the vascular density of the mature lung.

Reduced arterial number was also reported by Roberts et al. (19) and Wilson et al. (20). The short-term follow-up data provided by Roberts et al. (19) indicate that catch-up arterial growth may occur following hyperoxia exposure. The present study and the data of Wilson et al. (20), however, indicate that the arterial number remains reduced when evaluated in the adult rat. These differing results suggest that following the hyperoxic insult there is a tendency toward vascular recovery, but the adaptation is incomplete.

It could be hypothesized that impaired pulmonary vascularization inhibits the normal process of alveolar septal formation thus linking the two events. However, Myrick and Reid (25) have shown that septal formation precedes vascularization in the developing lung. The normal process of vascular and alveolar development appeared to be simultaneously affected by the hyperoxia. This is supported by the finding that the ratio of small pulmonary vessels per 100 alveoli was unchanged in the present study as well as the study of Wilson et al. (20). However, Wilson et al. (20) also demonstrated that more prolonged hyperoxia exposure reduces the ratio of small pulmonary vessels to alveoli suggesting that a vascular obliterative process may take place as well as vascular hypoplasia. Further dose response studies could better define the pathogenesis of these morphologic changes. It will be important to determine whether alveolar septation can be influenced independent of vascular changes.

Cardiovascular sequelae of neonatal hyperoxia exposure included the development of pulmonary hypertension and right ventricular hypertrophy. Percutaneous needle puncture of the right ventricle proved to be a useful, rapid, and reproducible method to assess maximum pulmonary arterial pressure $(32,33)$.

Wilson et al. (20) have suggested that the chronically exposed rat may adapt to an elevated inspired oxygen concentration. Return to normoxia might then stimulate pulmonary vasoconstriction similar to that seen in hypoxia-induced pulmonary hypertension. We found that oxygen saturation measurements in a group of rats following weaning from hyperoxia were similar to controls within $90 \mathrm{~h}$. This indicates that reactive pulmonary vasoconstriction stimulated by relative hypoxemia was unlikely. We also assessed the lability of subsequent pulmonary hypertension by measuring $\mathrm{RV}$ pressure during oxygen administration as well as in RA in the adult rat. No differences in RV pressures were found. Finally, the presence of long standing pulmonary hypertension was suggested in oxygen-exposed rats by the presence of right ventricular hypertrophy.

Pulmonary hypertension may be anatomically related to increased muscularization of pulmonary arterioles, reduced number of pulmonary vessels, or generalized hypoplasia of the pulmonary vascular tree. In the present model pulmonary hypertension may be due to a combination of these events. Muscularization of arterioles was increased, vessel counts were reduced, and hypoplasia of the vascular tree was suggested by a $25 \%$ 
decrease in the diameter of large pulmonary artery branches in hyperoxia-exposed rats. It should be noted, however, that muscularization of pulmonary arterioles was not dramatically increased as reported following chronic hypoxemia (34). The medial width/external diameter ratio of these vessels may have been increased in hyperoxia-exposed rats secondary to a decrease in external vessel diameter rather than a primary increase in muscularization.

We also observed changes in the distribution of the external oblique muscle surrounding pulmonary arteries of hyperoxiaexposed rats. In contrast to the increased thickness of the medial circular muscle, the external oblique muscle was found to be decreased or, in fact, absent. The pathogenesis of these divergent changes in the muscularization of pulmonary arterioles is not clear. Lane et al. (35) have speculated that pulmonary arterioles associated with oblique muscle are resistance vessels controlling pulmonary blood flow to alveoli. Vascular hypoplasia may have decreased pulmonary blood flow such that constant relaxation of resistance vessels was associated with atrophy of the oblique muscle. It is also possible that hyperoxia has a direct effect on the development of the oblique muscle, inhibiting its growth. The effect of oxygen concentration on the muscularization of pulmonary vessels needs to be explored further.

\section{SUMMARY}

The present investigation demonstrates that hyperoxia exposure limited to the newborn period is associated with morphologic and functional cardiopulmonary changes in the adult rat. Morphologic alterations include dysplastic alveolar and pulmonary vascular growth. Vascular pulmonary dysplasia was associated with chronic functional complications including pulmonary hypertension and increased pulmonary compliance.

The adult rat model of the toxic effects of neonatal hyperoxia exposure may be useful for future investigation of antioxidant effectiveness. Further investigation is also necessary to establish the risk of similar pulmonary abnormalities in human neonates exposed to elevated inspired oxygen concentration during comparable critical periods of lung growth and development.

Acknowledgments. The authors gratefully acknowledge the radiographic expertise of Pat Reeder, RT and the secretarial assistance of Karen Pickett.

\section{REFERENCES}

1. Kistler GS. Caldwell PRB. Weibel ER 1967 Development of fine structural damage to alvcolar and capillary lining walls in oxygen-poisoned rat lungs. $\mathrm{J}$ Cell Biol 33:605

2. Anderson WR. Strickland MB, Tsai SH, Haglin JJ 1973 Light microscopic and ultrastructural study of the adverse effects of oxygen therapy on the neonatal lung. Am J Pathol 73:327-348

3. Redding RA, Arai T. Douglas WHJ, Tsurutani H, Overs J 1975 Early changes in lungs of rats exposed to $70 \% \mathrm{O}_{2}$. J Appl Physiol 38:136-142

4. Frank L. Massaro D 1980 Oxygen toxicity. Am J Med 69:117-126

5. Dencke SM. Fanburg BL 1980 Normobaric oxygen toxicity of the lung. N Engl J Med 303:76-86

6. Smith FJC. Bennett GA. Hein JW, Thomson RM. Drinker CK 1932 Morphological changes in the lungs of rats living under compressed air conditions. J
Exp Med 56:79-87

7. Hellstrom B, Nergardh A 1965 The effect of high oxygen concentrations and hypothermia on the lung of the newborn mouse. Acta Paediatr Scand $54: 457-466$

8. Polgar G, Antagnoi W, Ferrigan LW, Martin EA, Gregg WP 1966 The effect of chronic exposure to $100 \%$ oxygen in newborn mice. Am J Sci 252:580587

9. Northway WH, Rosan RC, Shahinian L, Castellio RA, Gyepes MT, Durbridge T 1969 Radiologic and histologic investigation of pulmonary oxygen toxicity in newborn guinea pigs. Invest Radiol 4:148-155

10. Craig J, Rev-Kury LH, Kury G 1974 Oxygen toxicity in newborn rats. Lab Invest 31:425(abstr)

11. Ludwin SK, Northway WH, Bensch KG 1974 Oxygen toxicity in the newborn necrotizing bronchiolitis in mice exposed to 100 percent oxygen. Lab Invest $31: 425-435$

12. Bonikos DS, Bensch KG, Northway, WH 1976 Oxygen toxicity in the newborn Am J Pathol 85:623-250

13. Northway WH Jr, Rezeau L, Petriceks R, Bensch KG 1976 Oxygen toxicity in the newborn lung: reversal of inhibition of DNA synthesis in the mouse. Pediatrics 57:41-46

14. Yam J, Roberts RJ 1980 Oxygen-induced lung injury in the newborn piglet. Early Hum Dev 41:411-423

15. Graeber JE, Glaser BM 1985 Hyperoxia alters endothelial cell proliferation. Pediatr Res 19:155(abstr)

16. Bartlett D Jr 1970 Postnatal growth of the mammalian lung: influence of low and high oxygen tensions. Respir Physiol 9:58-64

17. Northway WH Jr, Petriceks R, Shahinian L 1972 Quantitative aspects of oxygen toxicity in the newborn: inhibition of lung DNA synthesis in the mouse. Pediatrics 50:67-72

18. Bucher JR, Roberts RJ 1981 The development of the newborn rat lung in hyperoxia: a dose-response study of lung growth, maturation, and changes in antioxidant enzyme activities. Pediatr Res 15:999-1008

19. Roberts RJ, Weesner KM, Bucher JR 1983 Oxygen-induced alterations in lung vascular development in the newborn rat. Pediatr Res 17:368-375

20. Wilson WL, Mullen M, Olley PM, Rabinovitch M 1985 Hyperoxia-induced pulmonary vascular and lung abnormalities in young rats and potential for recovery. Pediatr Res 19:1059-1067

21. Burri PH 1974 The postnatal growth of the rat lung. III. Morphology. Anat Rec 180:77-98

22. Dische $Z 1955$ Color reactions of nucleic acid components. In: Chagoff $E$ Davidson J (eds) The Nucleic Acids. Academic Press, Inc., New York

23. Lowry OH, Rosebrough HJ, Farr HL, Randall RJ 1951 Protein measurement with the folin phenol reagent. J Biol Chem 193:265-269

24. Mead J, Whittenberger JL, Radford EP 1957 Surface tension as a factor in pulmonary volume-pressure hysteresis. J Appl Physiol 10:191-196

25. Meyrick B, Reid L 1982 Pulmonary arterial and alveolar development in normal postnatal rat lung. Am Rev Respir Dis 125:468-473

26. Fulton RM, Hutchinson EC, Jones AM 1952 Ventricular weight in cardiac hypertrophy. Br Heart J 14:413-420

27. Scherle W 1970 A simple method for volumetry of organs in quantitative stereology. Mikroskopie 26:57-60

28. Dunnill MS 1962 Quantitative methods in the study of pulmonary pathology. Thorax 17:320-328

29. Meyrick B, Hislop A, Reid L 1978 Pulmonary arteries of the normal rat: the thick walled oblique muscle segment. J Anat 125:209-221

30. Hackney JD, Evans MJ, Bils RF, Spier CE, Jones MP 1977 Effects of oxygen at high concentrations and food deprivation on cell division in lung alveoli of mice. Exp Mol Pathol 26:350-358

31. Harrison GA 1971 Ultrastructural changes in rat lung during long-term exposure to oxygen. Exp Med Surg 29:96-107

32. Kumar R, Wagner R, Slankard ML, Abelmann WH 1971 Left and right ventricular pressures in mice. J Appl Physiol 30:424-426

33. Zhu YJ, Kradin R, Brandstetter RD, Staton G, Moss J, Hales CA 1983 Hypoxic pulmonary hypertension in the mast cell-deficient mouse. J Appl Physiol 54:680-686

34. Hislop A, Reid L 1976 New findings in pulmonary arteries of rats with hypoxiainduced pulmonary hypertension. Br J Exp Pathol 57:542-554

35. Lane BP, Zeidler M, Weinhold C, Drummond E 1983 Organization and structure of branches in the rat pulmonary arterial bed. Anat Rec 205:397403 